BMJ Open Sport \& Exercise Medicine

\section{Physical activity counselling in Ireland: a survey of doctors' knowledge, attitudes and self-reported practice}

To cite: O'Brien S, Prihodova L, Heffron M, et al. Physical activity counselling in Ireland: a survey of doctors knowledge, attitudes and selfreported practice. BMJ Open Sport \& Exercise Medicine 2019;5:e000572. doi:10.1136/ bmjsem-2019-000572

- Additional material is published online only. To view please visit the journal online (http://dx.doi.org/10.1136/ bmjsem-2019-000572).

Accepted 2 July 2019
Check for updates

(C) Author(s) (or their employer(s)) 2019. Re-use permitted under CC BY-NC. No commercial re-use. See rights and permissions. Published by BMJ.

${ }^{1}$ Department of Public Health HSE-West [Donegal, Sligo, Leitrim], Bridgewater House, Sligo, Ireland

${ }^{2}$ Royal College of Physicians of Ireland, Dublin, Ireland

Correspondence to Dr Sarah O'Brien; sarahob17@gmail.com

\section{ABSTRACT}

Objective Physical activity (PA) counselling has been shown to raise awareness of the importance of PA and to increase the rate of PA engagement among patients. While much attention has been paid to examining the knowledge, attitudes and practice of general practitioners in relation to PA counselling, there is less literature examining such issues in hospital-based doctors in Ireland and further afield. This study aimed to explore doctors' PA counselling practices and to analyse how this related to their level of PA knowledge, training and attitudes.

Methods An invitation to participate in an online survey was sent to 4692 members of the Royal College of Physicians of Ireland who were listed as having an address in Ireland. Descriptive and explorative analyses of the data were performed using IBM SPSS V.22.0.

Results A total of 595 valid responses were included (response rate $12.7 \% ; 42.7 \%$ male, $42.6 \pm 12.1$ years). The majority reported enquiring about PA levels $(88.0 \%)$ and providing PA counselling $(86.4 \%)$ in at least some of their patients. Doctors who saw it as their role and those who felt more effective/confident in providing PA counselling were significantly more likely to do so. A perceived lack of patient interest in PA and patient preference for pharmaceutical intervention were significant barriers to undertaking PA counselling.

Conclusion This study demonstrates the need for further education and training in PA counselling in Ireland with a particular focus on improving the attitudes and selfefficacy of doctors in this area at both undergraduate and postgraduate levels.

\section{INTRODUCTION}

The evidence base for the positive contribution that physical activity (PA) makes to health and well-being is well established and incontrovertible. ${ }^{1-3}$ Regular exercise reduces the risk of developing many chronic diseases, such as type two diabetes mellitus, ischaemic heart disease and dementia by at least $30 \%$ : a level of benefit greater than that often seen with pharmacotherapy. ${ }^{4}$ Physical inactivity is an important modifiable health risk factor which has been likened to a pandemic due to its significant health, economic, social and environmental consequences. ${ }^{5}$ In spite of
What are the new findings

- This study examines the knowledge, attitudes and practice of doctors working in Ireland in relation to physical activity (PA) counselling. It places a particular focus on hospital doctors and doctors engaged in specialist training: a relatively unexplored topic in Ireland and indeed, further afield.

- Doctors are undertaking PA counselling activities in practice despite an overall lack of training hours in PA counselling and behaviour change at both the undergraduate and postgraduate levels.

- Provider attitudes and level of seniority are associated with PA enquiry and counselling in practice.

- A perceived lack of patient interest in PA and a perceived patient preference for pharmaceutical intervention are significant barriers to undertaking PA counselling in practice.

How might it impact on clinical practice in the near future

It is recommended that postgraduate training bodies incorporate education and training on behaviour change and PA and its role as a preventive and therapeutic agent in health into medical curricula.

- Against the backdrop of the relatively recent introduction of the 'Making Every Contact Count' framework in Ireland, measures focusing on improving the attitudes and self-efficacy of doctors in the area of PA counselling may support the delivery of more frequent and effective brief interventions in this area.

this, the role of PA in health remains undervalued. $^{5}$

The National Physical Activity Plan for Ireland (NPAP) advises that adults should engage in at least $30 \mathrm{~min}$ of moderate-intensity to vigorous-intensity exercise on 5 days of each week, and that young people up to the age of 18 years should engage in at least 60 min of moderate-intensity to vigorous-intensity exercise every day. ${ }^{6}$ Brief advice, brief intervention and exercise prescription have been demonstrated to be cost-effective and to have a protracted positive effect on patients' PA levels. ${ }^{37-9}$ 
The approach to health in Ireland and further afield is in transition, with a greater emphasis being placed on primary prevention in an effort to reduce the burden of non-communicable disease. ${ }^{10-12}$ While many of the clinical guidelines on PA counselling place the onus for PA counselling on general practitioners (GPs), the recently introduced Making Every Contact Count strategy (MECC) in Ireland firmly places the responsibility of providing brief interventions to encourage positive behaviour change at the top of the agenda of all healthcare professionals (HCP). ${ }^{2}{ }^{11-16}$ Thus, it is hoped that brief interventions will become central to many medical consultations. ${ }^{4}$

While there is some literature which examines the practices of GPs in relation to the use of brief interventions for increasing PA in primary care, there is a dearth of evidence examining the PA counselling practices of hospital-based doctors in Ireland and further afield, including those doctors who are engaged in ongoing specialist training. ${ }^{17} 18$ The Royal College of Physicians of Ireland (RCPI) is a recognised postgraduate medical training body in Ireland and comprises six of the 13 Irish postgraduate specialist training bodies, namely: the Irish Committee on Higher Medical Training, the Faculty of Public Health Medicine, the Faculty of Occupational Medicine, the Faculty of Pathology, the Faculty of Paediatrics and the Institute of Obstetricians and Gynaecologists. ${ }^{19}$ The aim of this project was to describe RCPI members' and trainees' practices of asking and advising about PA and to analyse how this related to their level of PA knowledge, training, attitudes and perceived barriers to this practice.

\section{METHODS \\ Sample}

This was a cross-sectional study of members and trainees of the RCPI with an address in Ireland in 2017. Members who were retired, working outside of Ireland or who did not have any clinical contact with patients were excluded from the study. The total sample size was calculated as 4692. The study protocol was reviewed and approved by the RCPI Research Ethics Committee (application number 53). This research was done without patient involvement.

\section{Measures}

The survey tool was designed to capture demographic and employment data as well as data on doctors' self-reported attitudes, knowledge, training and behaviour in relation to PA counselling. Questions were drawn from two previously validated survey instruments. ${ }^{1020}$ Doctors' PA knowledge was examined over the course of four questions using a combination of forced choice items and the use of 10-point Likert Scales. Attitudes in relation to PA enquiry and counselling were assessed across four questions pertaining to perceived effectiveness and importance using a 10-point Likert scale, while doctors' levels of PA enquiry and counselling were examined in four questions by asking about the proportions of their patients who were in receipt of such activities during clinical encounters. Three questions were created de novo to capture data on medical specialty and clinical contact for a wide range of doctors. The draft questionnaire was piloted by sending it to a sample of the study population. A total of 30 RCPI members were contacted at random by email and asked to participate in the pilot study. Feedback was gathered to identify ambiguities in the questions and to assess how long, on average, the survey took to complete. Psychometric testing was also undertaken using Cronbach's alpha coefficient to explore the internal consistency of the questionnaire.

RCPI members were invited to participate via email with three email contacts containing a link to the survey circulated over the course of 3 months.

\section{Data analysis}

Descriptive and explorative analyses of the data were performed using the IBM SPSS V.22.0. Independent t-tests and $\chi^{2}$ tests were used to determine differences between groups.

The primary outcome variables-PA enquiries and counselling (proportion of doctors who reported enquiring about PA habits and the proportion who reported providing verbal or written advice or exercise prescriptions to their patients regarding PA) were examined using descriptive analyses, as well as recoded as dichotomous variables ('PA enquiry: yes/no' and 'PA counselling: yes/no'). Analyses to compare PA counselling activities according to level of seniority were undertaken with participants divided into the two groups: 'doctors who have completed specialist training' (ie, consultants and GPs) and 'doctors who have not completed specialist training' (ie, non-consultant hospital doctors or NCHDs) as level of seniority has been shown to impact on PA counselling activities in previous studies. $^{21-24}$

A binary logistic regression model was used to evaluate interactions between the dependent variables ('PA enquiry' and 'PA counselling') and the independent variables (doctor characteristics, level of postgraduate education received in the area of health promotion, attitudes towards and knowledge of PA counselling and perceived barriers to PA counselling). Based on a review of the literature, the barriers were divided into three categories: barriers to PA counselling in practice (a lack of time, a lack of financial compensation, a doctor not seeing it as their role, counselling regarding other lifestyle changes viewed as more important); patient-related barriers (a perceived lack of patient interest in PA and a perceived patient preference for pharmaceutical interventions) and barriers due to a lack of resources (a lack of supportive guidelines and tools, a lack of evidence to support PA counselling in practice and a lack of undergraduate education). 


\section{RESULTS}

\section{Response rate and demographics}

In total, 792 responses were received, giving an overall response rate of $16.0 \%$. Out of these, $161 \mathrm{did}$ not fit the inclusion criteria and a further 36 respondents did not complete the survey in its entirety and were therefore excluded from further analyses. This gave a valid response rate of $12.7 \%$, with 595 valid responses.

The average age of respondents was $42.6(\mathrm{SD}=12.1)$ years. Of the respondents, $254(42.7 \%)$ were male and $335(56.3 \%)$ were female. With regard to training, 527 $(88.6 \%)$ completed their undergraduate training in Ireland, 19 (3.2\%) completed training in the European Union (EU and $32(5.4 \%)$ of the respondents completed their training outside of the EU. With regard to job description, $316(53.1 \%)$ of respondents were Consultants, 215 (36.1\%) were NCHDs and 55 (9.2\%) were GPs (table 1).

\section{Doctors' self-reported clinical practice}

An examination of the data regarding doctors' self-reported practice found that $88.0 \%$ enquired about PA levels and $86.2 \%$ provided verbal PA counselling to at least some of their patients (table 2). The majority of participants reported that they did not provide either written advice $(82.6 \%)$ or prescriptions $(89.3 \%)$ regarding PA.

The sex and age of respondents were not significantly associated with PA enquiry and counselling. However, significant differences were found when respondents were grouped according to job seniority, with a higher proportion of respondents in more senior positions reporting enquiring and counselling activities (table 3 ).

\section{Doctors' knowledge of, and attitudes towards, PA counselling}

The level of awareness of the NPAP for Ireland was low among respondents with just $10.1 \%$ indicating that they were familiar with the report. The majority of respondents $(64.1 \%)$ indicated the correct weekly levels of PA recommended by the National PA Guidelines for Ireland (table 1). Respondents who were familiar with the NPAP were significantly more likely to report PA enquiry and counselling activities than those who were not familiar with the NPAP (table 3).

In relation to the number of hours of postgraduate training received in health promotion, and more specifically in PA counselling, the most common responses were less than 4 hours $(29.0 \%)$ and none $(57.8 \%)$, respectively (table 1). Those who received 4-10 hours of postgraduate education in health promotion were significantly more likely to provide PA counselling. Having received between 4 and 10 or 11 and 40 hours of postgraduate training in PA counselling was significantly associated with asking patients about their PA levels and with providing counselling (table 4).

Despite the low number of postgraduate hours dedicated to health promotion and PA counselling education, many participants rated their knowledge and confidence to perform PA counselling as fair to very good (table 1).
There was a statistically significant difference between doctors who had completed specialist training and those who had not, with senior doctors reporting a significantly higher level of knowledge to provide PA counselling, $\mathrm{t}(545)=3.5, \mathrm{p}<0.001$ (table 1 ). There was a significant association between level of knowledge in the provision of PA counselling and enquiring and counselling regarding PA (table 4).

There was also a significant difference in confidence levels between respondents when grouped according to level of seniority with doctors who had completed specialist training having a significantly higher average score when compared with NCHDs, $\mathrm{t}(545)=4.5, \mathrm{p}<0.001$ (table 1). Furthermore, confidence was identified as an important factor in undertaking PA counselling activities, with a significant association between confidence and PA enquiry and counselling activities observed (table 4).

Doctors' perceived level of self-efficacy in effecting behaviour change was mostly reported as ineffective $(49.9 \%)$ (table 1). Senior doctors reported a significantly higher average level of self-efficacy in providing PA counselling than NCHDs, $t(545)=5.7, \quad \mathrm{p}<0.001$ (table 1). A doctor's self-efficacy was significantly associated with asking and advising regarding PA, although it appears that even those who feel very ineffective or ineffective still raise the issue of PA during consultations (table 4).

With regard to the priority that doctors place on PA counselling in practice, the most frequent responses were that it was considered either a medium or high priority. There was a significant difference when participants were grouped according to level of seniority, with senior doctors reporting a higher average score for the level of priority that they attributed to PA counselling in practice when compared with NCHDs, $\mathrm{t}(545)=5.5, \mathrm{p}<0.001$ (table 1). There was also a significant association between asking and advising regarding PA levels and the priority a doctor placed on addressing PA in consultations, with those who placed a higher priority on PA counselling also significantly more likely to undertake PA counselling activities in practice (table 4 ).

\section{Barriers to the provision of PA counselling in practice}

Patient preference $(p \leq 0.001)$ and a lack of tools $(p \leq 0.01)$, time $(p \leq 0.05)$ and undergraduate education $(p \leq 0.001)$ in the area of PA prescribing were significant barriers to enquiring about PA in practice. Seeing it as the role of the doctor was also significantly associated with enquiring about PA levels $(\mathrm{p} \leq 0.001)$.

A lack of PA guidelines $(p \leq 0.01)$, patient preference for pharmaceutical intervention $(\mathrm{p} \leq 0.001)$, a lack of time $(p \leq 0.05)$ and tools $(p \leq 0.01)$ and a lack of undergraduate education in the area of PA prescribing $(p \leq 0.05)$ were identified as significant barriers to PA counselling in practice. There was a significant association between a doctor seeing it as their role and providing PA counselling $(\mathrm{p} \leq 0.001)$. 
Table 1 Characteristics of survey participants

\begin{tabular}{|c|c|c|c|}
\hline & All & Completed specialist training & NCHD \\
\hline Characteristic & $\begin{array}{l}\text { Total }(\mathrm{n}=595) ; \\
\text { Mean (SD) } \\
\mathrm{n}(\%)\end{array}$ & $\begin{array}{l}\text { Total }(\mathrm{n}=380) \\
\text { Mean }(\mathrm{SD}) \\
\mathrm{n}(\%)\end{array}$ & $\begin{array}{l}\text { Total }(\mathrm{n}=215) \\
\text { Mean (SD) } \\
\mathrm{n}(\%)\end{array}$ \\
\hline Age (years) & $42.6(12.1 \%)$ & $49.0(10.0 \%)$ & $31.5(5.7 \%)$ \\
\hline $20-34$ & $203(34.4 \%)$ & $24(6.3 \%)$ & $179(83.3 \%)$ \\
\hline $35-49$ & $213(36.1 \%)$ & $184(48.4 \%)$ & $29(13.5 \%)$ \\
\hline $50-64$ & $145(24.6 \%)$ & $139(36.6 \%)$ & $6(2.8 \%)$ \\
\hline $65+$ & $29(4.9 \%)$ & $29(7.6 \%)$ & $0(0.0 \%)$ \\
\hline Missing values & $5(0.8 \%)$ & $4(1.1 \%)$ & $1(0.5 \%)$ \\
\hline \multicolumn{4}{|l|}{ Sex } \\
\hline Male & $254(42.7 \%)$ & $188(49.5 \%)$ & $66(30.7 \%)$ \\
\hline Female & $335(56.3 \%)$ & $191(50.3 \%)$ & $144(67.0 \%)$ \\
\hline Prefer not to answer & $6(1.0 \%)$ & $1(0.3 \%)$ & $5(2.3 \%)$ \\
\hline \multicolumn{4}{|l|}{ Job title } \\
\hline Consultant & $316(53.1 \%)$ & & \\
\hline $\mathrm{NCHD}$ & $215(36.1 \%)$ & & \\
\hline GP & $55(9.2 \%)$ & & \\
\hline Missing values & $9(1.5 \%)$ & & \\
\hline \multicolumn{4}{|c|}{ Postgraduate training hours received on health promotion } \\
\hline None & $153(27.6 \%)$ & $81(22.7 \%)$ & $72(36.4 \%)$ \\
\hline$<4$ & $161(29.0 \%)$ & $77(21.6 \%)$ & $84(42.4 \%)$ \\
\hline $4-10$ & $76(13.7 \%)$ & $59(16.5 \%)$ & $17(8.6 \%)$ \\
\hline $11-40$ & $56(10.1 \%)$ & $45(12.6 \%)$ & $11(5.6 \%)$ \\
\hline$>40$ & $71(12.8 \%)$ & $61(17.1 \%)$ & $10(5.1 \%)$ \\
\hline Don't know & $38(6.8 \%)$ & $34(9.5 \%)$ & $4(2.0 \%)$ \\
\hline \multicolumn{4}{|c|}{ Postgraduate training hours received on PA counselling } \\
\hline None & $321(57.8 \%)$ & $184(51.5 \%)$ & $137(69.2 \%)$ \\
\hline$<4$ & $125(22.5 \%)$ & $78(21.8 \%)$ & $47(23.7 \%)$ \\
\hline $4-10$ & $50(9.0 \%)$ & $40(11.2 \%)$ & $10(5.1 \%)$ \\
\hline $11-40$ & $16(2.9 \%)$ & $16(4.5 \%)$ & $0(0.0 \%)$ \\
\hline$>40$ & $25(4.5 \%)$ & $22(6.2 \%)$ & $3(1.4 \%)$ \\
\hline Don't know & $18(3.2 \%)$ & $17(4.8 \%)$ & $1(0.5 \%)$ \\
\hline \multicolumn{4}{|l|}{ Priority placed on PA counselling in practice } \\
\hline Low/ Very low & $117(21.1 \%)$ & $57(16.0 \%)$ & $60(30.3 \%)$ \\
\hline Medium & $168(30.3 \%)$ & $94(26.3 \%)$ & $74(37.4 \%)$ \\
\hline High/Very high & $270(47 \%)$ & $206(57.7 \%)$ & 64 (32.3\%) \\
\hline $\begin{array}{l}\text { Self-rated knowledge of how to perform PA } \\
\text { counselling }\end{array}$ & $5.3(2.3)$ & $5.6(2.3)$ & $4.9(2.3)$ \\
\hline $1-2$ (poor) & $68(12.2 \%)$ & $33(9.2 \%)$ & $35(17.7 \%)$ \\
\hline $3-4$ & $139(25.1 \%)$ & $85(23.8 \%)$ & $54(27.3 \%)$ \\
\hline $5-6$ & $153(27.6 \%)$ & $98(27.4 \%)$ & $55(27.8 \%)$ \\
\hline $7-8$ & $149(26.9 \%)$ & $108(30.2 \%)$ & $41(20.7 \%)$ \\
\hline 9-10 (excellent) & $46(8.3 \%)$ & $33(9.2 \%)$ & $13(6.5 \%)$ \\
\hline $\begin{array}{l}\text { Self-rated confidence to perform PA } \\
\text { counselling }\end{array}$ & $5.3(2.4)$ & $5.7(2.3)$ & $4.7(2.3)$ \\
\hline $1-2$ (poor) & 73 (13.1\%) & 36 (10.1\%) & 37 (18.7\%) \\
\hline
\end{tabular}


Table 1 Continued

\begin{tabular}{|c|c|c|c|}
\hline & All & Completed specialist training & NCHD \\
\hline Characteristic & $\begin{array}{l}\text { Total }(\mathrm{n}=595) ; \\
\text { Mean (SD) } \\
\mathrm{n}(\%)\end{array}$ & $\begin{array}{l}\text { Total }(\mathrm{n}=380) ; \\
\text { Mean }(\mathrm{SD}) \\
\mathrm{n}(\%)\end{array}$ & $\begin{array}{l}\text { Total }(\mathrm{n}=215) \\
\text { Mean }(S D) \\
\mathrm{n}(\%)\end{array}$ \\
\hline $3-4$ & $142(25.6 \%)$ & $81(22.7 \%)$ & $61(30.8 \%)$ \\
\hline $5-6$ & $150(27 \%)$ & $97(27.2 \%)$ & $53(26.7 \%)$ \\
\hline $7-8$ & $136(24.5 \%)$ & $102(28.6 \%)$ & $34(17.2 \%)$ \\
\hline 9-10 (excellent) & $54(9.7 \%)$ & $41(11.5 \%)$ & $13(6.5 \%)$ \\
\hline \multicolumn{4}{|c|}{ Self-rated efficacy in altering patients' PA habits } \\
\hline Very ineffective & $47(8.5 \%)$ & $22(6.2 \%)$ & $25(12.6 \%)$ \\
\hline Ineffective & $277(49.9 \%)$ & $154(43.1 \%)$ & $123(62.1 \%)$ \\
\hline Effective & $212(38.2 \%)$ & $167(46.8 \%)$ & $45(22.7 \%)$ \\
\hline Very effective & $19(3.4 \%)$ & $14(3.9 \%)$ & $5(2.5 \%)$ \\
\hline \multicolumn{4}{|l|}{ Level of familiarity with the National PA Plan } \\
\hline Yes, I'm familiar with it & $56(10.1 \%)$ & $44(12.3 \%)$ & $12(6.1 \%)$ \\
\hline Yes, I've heard of it but haven't read it & $181(32.6 \%)$ & $135(37.8 \%)$ & $46(23.2 \%)$ \\
\hline No, I'm not familiar with it & $318(57.3 \%)$ & $178(49.9 \%)$ & $140(70.7 \%)$ \\
\hline \multicolumn{4}{|l|}{ Recommended weekly levels of PA } \\
\hline Less than 90 min & $145(26.0 \%)$ & $85(23.8 \%)$ & $60(30.3 \%)$ \\
\hline $150 \mathrm{~min}$ & $356(64.1 \%)$ & $232(65.0 \%)$ & 124 (62.6\%) \\
\hline $300 \mathrm{~min}$ & $54(9.7 \%)$ & $40(11.2 \%)$ & $14(7.1 \%)$ \\
\hline
\end{tabular}

GP, general practitioner; NCHD, non-consultant hospital doctor; PA, physical activity.

\section{Factors associated with PA enquiry and counselling: multivariate analysis}

When analysing the factors associated with enquiring about patients' PA habits, the model produced by binary logistical regression explained $41.0 \%$ of the variance. Doctors were significantly more likely to enquire about the PA habits of their patients if they placed a higher priority on PA counselling in practice and if they felt more confident and effective in helping their patients to achieve behavioural change (table 5).

When analysing the factors associated with providing PA counselling in practice, the model produced by binary logistical regression explained $54.0 \%$ of the variance. Doctors were significantly more likely to undertake PA counselling in practice if they placed a higher priority on PA counselling and if they felt confident in providing it. Patient-related barriers (ie, a perceived lack of patient interest and patient preference for a pharmaceutical intervention) were identified as significant deterrents to PA counselling in practice (table 5).

\section{DISCUSSION}

This study has found that doctors are undertaking PA counselling activities in practice despite an overall deficit in undergraduate and postgraduate training in PA counselling and behaviour change. Furthermore, HCP attitudes towards PA counselling were significantly associated with undertaking such activities in practice. A perceived lack of patient interest in PA and a perceived patient preference for pharmaceutical intervention were identified as significant barriers to PA counselling. However, it is important to note from the outset that the sub-optimal response rate $(12.7 \%)$ limits the external validity of the findings and the ability to draw firm

Table 2 Doctors' self-reported clinical practice

\begin{tabular}{|c|c|c|c|c|c|}
\hline & No & $\begin{array}{l}\text { Yes, in }<25 \% \text { of } \mathrm{my} \\
\text { patients }\end{array}$ & $\begin{array}{l}\text { Yes, in } 25 \%-49 \% \text { of } \\
\text { my patients }\end{array}$ & $\begin{array}{l}\text { Yes, in } 50 \%-74 \% \text { of } \\
\text { my patients }\end{array}$ & $\begin{array}{l}\text { Yes, in } 75 \%-100 \% \\
\text { of my patients }\end{array}$ \\
\hline PA intervention & n (\%) & n (\%) & n (\%) & n (\%) & n (\%) \\
\hline Enquire about PA levels & $63(12.0)$ & $122(23.3)$ & $98(18.7)$ & $120(22.9)$ & $120(22.9)$ \\
\hline Provide verbal counselling on PA & $72(13.8)$ & $143(27.3)$ & $118(22.6)$ & $111(21.2)$ & $79(15.1)$ \\
\hline Provide written counselling on PA & $432(82.6)$ & 59 (11.3) & $12(2.3)$ & $11(2.1)$ & $9(1.7)$ \\
\hline Provide a PA prescription & 467 (89.3) & $33(6.3)$ & $8(1.5)$ & $9(1.7)$ & $6(1.1)$ \\
\hline
\end{tabular}

PA, physical activity. 
Table 3 Association of doctor characteristics with PA enquiry/counselling

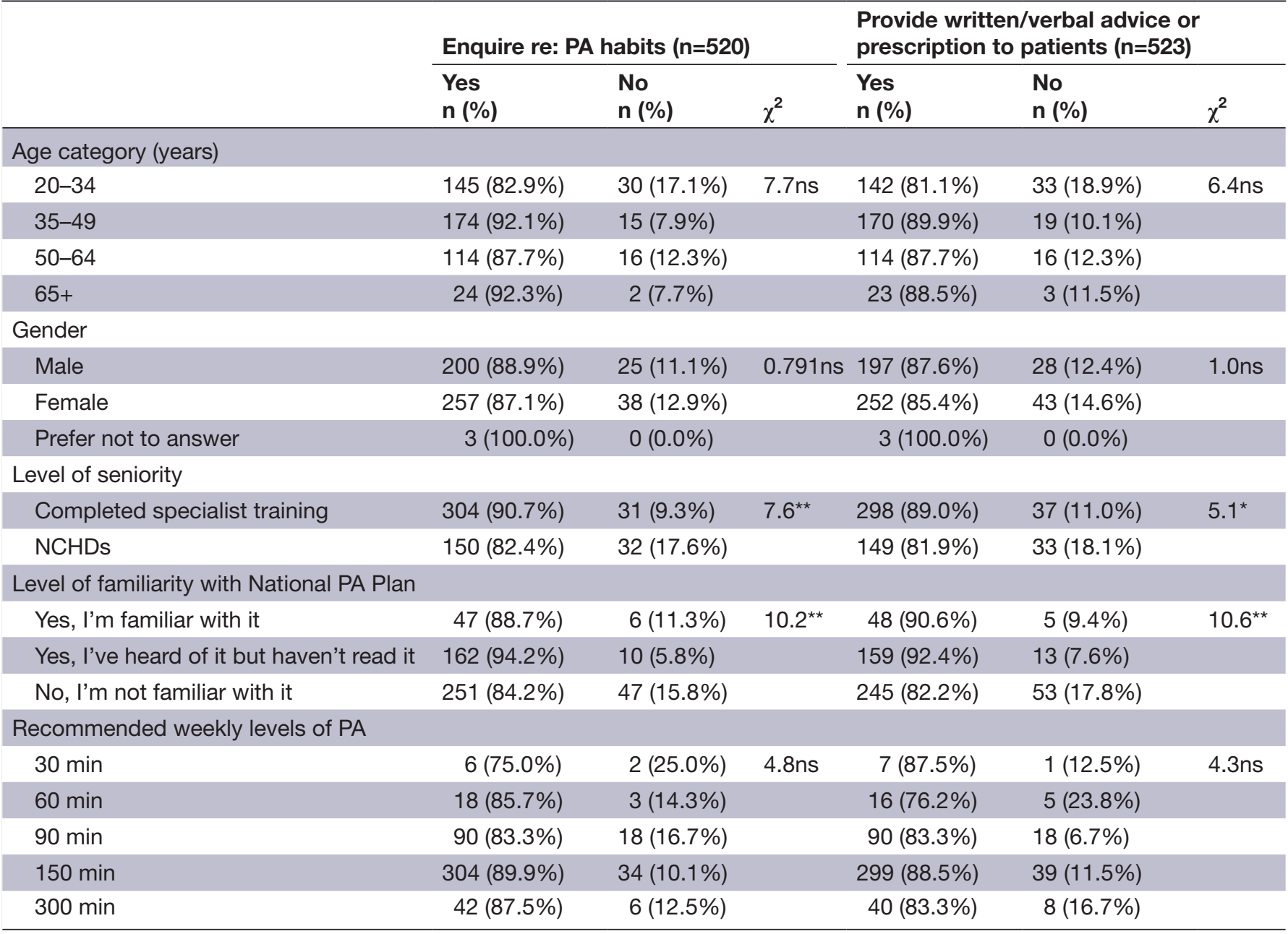

${ }^{*} \mathrm{p} \leq 0.05 ;{ }^{* *} \mathrm{p} \leq 0.01 ;{ }^{* * *} \mathrm{p} \leq 0.001$.

NCHD, non-consultant hospital doctor; PA, physical activity; ns, not significant.

conclusions. It must be acknowledged that PA counselling is likely to be more relevant to some medical specialties over others and while we sought to compare and contrast doctors' PA counselling activities by specialty, this was not possible due to low response rates within the individual specialties (online supplementary table 1). Nonetheless, this convenience sample acts as an indicator of potential unmet need at both the NCHD and specialist level that warrants further exploration.

\section{Doctors' self-reported practice}

This sample of RCPI members indicated high rates of reported PA enquiry and counselling activities. However, survey participants indicated that they do not engage in PA counselling with all of their patients and this is in keeping with the international literature. ${ }^{10172125}$ Furthermore, rates of written counselling and the provision of PA prescriptions to patients were much lower. ${ }^{21}$ Bull et $a l^{26}$ posit that doctors feel more confident in providing general advice as opposed to specific advice on the type and duration of exercise and suggest that the provision of additional training and evidence-informed resources in this area may support more effective practice. This need has been recognised at the international level through the provision of PA counselling frameworks and exercise prescription toolkits. ${ }^{27} 28$ Further qualitative research should be undertaken in Ireland in an effort to gain a deeper understanding of the barriers to undertaking PA counselling and prescribing in practice.

\section{Doctors' knowledge, confidence and attitudes towards PA counselling in practice}

This study has identified a deficit in the knowledge, attitudes and practice of doctors in the area of PA counselling in Ireland. Furthermore, this survey also demonstrates a lack of teaching in this area at both undergraduate and postgraduate levels. While changes to undergraduate curricula are in process, there remains an unmet need in Ireland for education in PA counselling during postgraduate years. $^{29}$

It appears that doctors most effectively learn behaviour change counselling skills through interactive learning in association with a limited amount of didactic teaching. ${ }^{3031}$ The use of tools to support the systematic screening and 
Table 4 Association of doctors' PA counselling knowledge and attitudes with PA enquiry/counselling

Enquire re: PA habits $(n=523)$

\begin{tabular}{|c|c|c|c|c|c|c|}
\hline & & & & \\
\hline & $\begin{array}{l}\text { Yes } \\
\text { n (\%) }\end{array}$ & $\begin{array}{l}\text { No } \\
\text { n (\%) }\end{array}$ & $\chi^{2}$ & $\begin{array}{l}\text { Yes } \\
\text { n (\%) }\end{array}$ & $\begin{array}{l}\text { No } \\
\text { n (\%) }\end{array}$ & $\chi^{2}$ \\
\hline \multicolumn{7}{|c|}{ Postgraduate hours received in health promotion } \\
\hline None & $117(81.3 \%)$ & $27(18.8 \%)$ & $13.7 \mathrm{~ns}$ & $114(79.2 \%)$ & $30(20.8 \%)$ & $13.3^{\star}$ \\
\hline$<4$ hours & $130(86.7 \%)$ & $20(13.3 \%)$ & & $128(85.3 \%)$ & $22(14.7 \%)$ & \\
\hline $4-10$ hours & $68(97.1 \%)$ & $2(2.9 \%)$ & & $66(94.3 \%)$ & $4(5.7 \%)$ & \\
\hline $11-40$ hours & $49(92.5 \%)$ & $4(7.5 \%)$ & & $49(92.5 \%)$ & $4(7.5 \%)$ & \\
\hline$>40$ hours & $62(91.2 \%)$ & $6(8.8 \%)$ & & $62(91.2 \%)$ & $6(8.8 \%)$ & \\
\hline Don’t know & $34(89.5 \%)$ & $4(10.5 \%)$ & & $33(86.8 \%)$ & $5(13.2 \%)$ & \\
\hline \multicolumn{7}{|c|}{ Postgraduate hours received in PA counselling } \\
\hline None & $251(83.7 \%)$ & $49(16.3 \%)$ & $16.4^{\star *}$ & $242(80.7 \%)$ & $58(19.3 \%)$ & $23.2^{\star * *}$ \\
\hline$<4$ hours & $103(89.6 \%)$ & $12(10.4 \%)$ & & $104(90.4 \%)$ & $11(9.6 \%)$ & \\
\hline $4-10$ hours & $48(98.0 \%)$ & $1(2.0 \%)$ & & $49(100.0 \%)$ & $0(0.0 \%)$ & \\
\hline $11-40$ hours & $16(100.0 \%)$ & $0(0.0 \%)$ & & $16(100.0 \%)$ & $0(0.0 \%)$ & \\
\hline$>40$ hours & $25(100.0 \%)$ & $0(0.0 \%)$ & & $24(96.0 \%)$ & $1(4.0 \%)$ & \\
\hline Don’t know & $17(94.4 \%)$ & $1(5.6 \%)$ & & $17(94.4 \%)$ & $1(5.6 \%)$ & \\
\hline \multicolumn{7}{|c|}{ Efficacy in helping patients achieve change in PA habits } \\
\hline Very ineffective & $24(57.1 \%)$ & $18(42.9 \%)$ & $65.9^{\star \star \star}$ & $21(50.0 \%)$ & $21(50.0 \%)$ & $74.8^{\star \star \star}$ \\
\hline Ineffective & $218(83.8 \%)$ & $42(16.2 \%)$ & & $215(82.7 \%)$ & $45(17.3 \%)$ & \\
\hline Effective & $200(99.0 \%)$ & $2(1.0 \%)$ & & $198(98.0 \%)$ & $4(2.0 \%)$ & \\
\hline Very effective & $18(94.7 \%)$ & $1(5.3 \%)$ & & $18(94.7 \%)$ & $1(5.3 \%)$ & \\
\hline \multicolumn{7}{|c|}{ Priority placed on PA counselling in practice } \\
\hline Very low & $10(43.5 \%)$ & $13(56.5 \%)$ & $103.2^{\star * *}$ & $5(21.7 \%)$ & $18(78.3 \%)$ & $156.9^{\star \star \star}$ \\
\hline Low & $56(67.5 \%)$ & 27 (32.5\%) & & $51(61.4 \%)$ & $32(38.6 \%)$ & \\
\hline Medium & $140(88.1 \%)$ & $19(11.9 \%)$ & & $144(90.6 \%)$ & $15(9.4 \%)$ & \\
\hline High & $126(96.9 \%)$ & $4(3.1 \%)$ & & $125(96.2 \%)$ & $5(3.8 \%)$ & \\
\hline \multicolumn{7}{|c|}{ Self-rated knowledge of how to perform PA counselling } \\
\hline Very poor & $41(64.1 \%)$ & $23(35.9 \%)$ & $45.4^{\star \star *}$ & $34(53.1 \%)$ & $30(46.9 \%)$ & $75.6^{\star \star \star}$ \\
\hline Poor & $113(87.6 \%)$ & $16(12.4 \%)$ & & $111(86.0 \%)$ & $18(14.0 \%)$ & \\
\hline Fair & $129(89.0 \%)$ & $16(11.0 \%)$ & & $130(89.7 \%)$ & $15(10.3 \%)$ & \\
\hline Good & $137(96.5 \%)$ & $5(3.5 \%)$ & & $137(96.5 \%)$ & $5(3.5 \%)$ & \\
\hline Very good/excellent & $40(93.0 \%)$ & $3(7.0 \%)$ & & $40(93.0 \%)$ & $3(7.0 \%)$ & \\
\hline \multicolumn{7}{|c|}{ Self-rated confidence to perform PA counselling } \\
\hline Very poor & $42(62.7 \%)$ & $25(37.3 \%)$ & $58.7^{\star \star *}$ & 34 (50.7\%) & 33 (49.3\%) & $102.4^{\star \star \star}$ \\
\hline Poor & $110(84.6 \%)$ & $20(15.4 \%)$ & & 105 (80.8\%) & 25 (19.2\%) & \\
\hline Fair & 128 (90.8\%) & $13(9.2 \%)$ & & 134 (95.0\%) & 7 (5.0\%) & \\
\hline Good & 132 (98.5\%) & $2(1.5 \%)$ & & 131 (97.8\%) & $3(2.2 \%)$ & \\
\hline Very good/excellent & $48(94.1 \%)$ & $3(5.9 \%)$ & & $48(94.1 \%)$ & $3(5.9 \%)$ & \\
\hline
\end{tabular}

Provide written/verbal advice or prescription to patients $(n=523)$

${ }^{*} \mathrm{p} \leq 0.05 ;{ }^{* *} \mathrm{p} \leq 0.01 ;{ }^{* * *} \mathrm{p} \leq 0.001$.

PA, physical activity; ns, not significant.

delivery of brief interventions is also recommended. ${ }^{731} 32$ Furthermore, the need for frequent refresher courses to keep skills up to date has been acknowledged..$^{30}$ MECC aims to embed the delivery of health-promoting interventions by HCPs into every contact a patient has with the health services. ${ }^{12}$ A central component of the implementation of MECC is the training of HCPs which is currently being rolled out. ${ }^{29}$ It is likely that this programme will meet some of the aforementioned training needs. ${ }^{29}$ However, the need to develop a postgraduate curriculum for HCPs 
Table 5 Factors associated with increased likelihood of doctors enquiring about patients' PA habits/undertaking PA counselling activities in practice

\begin{tabular}{|c|c|c|c|c|}
\hline \multirow[b]{2}{*}{ Doctor characteristic } & \multicolumn{2}{|c|}{$\begin{array}{l}\text { Factors associated with enquiring } \\
\text { about patients' PA habits }\end{array}$} & \multicolumn{2}{|c|}{$\begin{array}{l}\text { Factors associated with } \\
\text { undertaking PA counselling }\end{array}$} \\
\hline & $\operatorname{Exp}(B)$ & $(95 \% \mathrm{Cl})$ & $\operatorname{Exp}(B)$ & $(95 \% \mathrm{Cl})$ \\
\hline Age (years) & 0.96 & 0.91 to 1.00 & 0.99 & 0.94 to 1.04 \\
\hline Male gender† & 1.30 & 0.62 to 2.70 & 1.25 & 0.58 to 2.72 \\
\hline Doctors who have completed specialist trainingł & 2.80 & 0.92 to 8.53 & 1.32 & 0.41 to 4.27 \\
\hline $\begin{array}{l}\text { Number of postgraduate hours training received in } \\
\text { health promotion }\end{array}$ & 1.01 & 0.79 to 1.29 & 1.03 & 0.80 to 1.32 \\
\hline $\begin{array}{l}\text { Number of postgraduate hours received in PA } \\
\text { counselling }\end{array}$ & 1.00 & 0.65 to 1.56 & 1.10 & 0.66 to 1.82 \\
\hline $\begin{array}{l}\text { Level of priority placed on PA counselling in } \\
\text { practice }\end{array}$ & $2.48^{*}$ & 1.63 to 3.75 & $2.82^{*}$ & 1.77 to 4.48 \\
\hline Self-rated knowledge in PA counselling & 0.86 & 0.64 to 1.61 & 0.83 & 0.60 to 1.15 \\
\hline Self-rated confidence in providing PA counselling & $2.12^{* *}$ & 1.09 to 2.05 & $2.12^{\star *}$ & 1.47 to 3.05 \\
\hline $\begin{array}{l}\text { Level of efficacy in helping patients achieve change in } \\
\text { the area of PA }\end{array}$ & $2.12^{* * *}$ & 1.08 to 4.16 & 1.64 & 0.78 to 3.46 \\
\hline Practice-related barriers to PA counselling & 0.94 & 0.52 to 1.69 & 1.04 & 0.55 to 2.00 \\
\hline Patient-related barriers to PA counselling & 1.26 & 0.88 to 1.82 & $1.50^{*}$ & 1.01 to 2.22 \\
\hline Resource-related barriers to PA counselling & 1.17 & 0.73 to 1.90 & 1.49 & 0.89 to 2.49 \\
\hline \multicolumn{5}{|l|}{ HEPA categories§ } \\
\hline Inactive & 1.16 & 0.31 to 4.32 & 0.96 & 0.23 to 3.90 \\
\hline Minimally active & 1.30 & 0.64 to 2.62 & 1.19 & 0.57 to 2.50 \\
\hline Nagelkerke $\mathbf{R}^{2}$ & $41.0 \%$ & & $54.0 \%$ & \\
\hline
\end{tabular}

${ }^{*} \mathrm{p} \leq 0.001 ;{ }^{* *} \mathrm{p} \leq 0.01 ;{ }^{* \star *} \mathrm{p} \leq 0.05$. $\mathrm{R}^{2}$ : Total variance explained by the model.

†Reference category: Female gender.

†Reference category: NCHDs.

§Reference category: HEPA.

HEPA, Health-Enhancing Physical Activity; NCHD, non-consultant hospital doctor; PA, physical activity.

to systematically address health behaviour change is also recognised. ${ }^{12}$ Furthermore, ensuring that MECC training forms a part of the mandatory training programme for health professional training bodies, along with the development of screening tools and referral pathways, will further support doctors to engage in these health promoting activities as part of their routine practice. ${ }^{12}$

\section{Patient-related barriers to PA counselling activities}

In keeping with the evidence base, multivariate analyses revealed that patient preference for a pharmaceutical intervention and a lack of patient interest in PA were significant barriers to undertaking PA counselling during consultations. ${ }^{33-35}$ The literature suggests that a GP's behaviour can be influenced by patient expectations and the fear of causing offence. ${ }^{2833}{ }^{35}$ Interestingly, the evidence base from the patient's perspective suggests that patient resistance may be less of a barrier than doctors think, with one systematic review indicating that as many as one-in-four people say they would be more physically active if advised by a GP or a nurse. ${ }^{8} \mathrm{~A}$ shift in thinking is required by doctors and patients alike to use PA not merely as an optional adjunct to treatment, but also as a robust and acceptable therapeutic option in its own right. $^{36}$

\section{Strengths and limitations}

This study was strengthened by several factors. The use of a previously validated questionnaire facilitated the collection of robust data. The piloting and psychometric testing of the questionnaire improved face validity and internal consistency. Consideration was given to how this study could optimise response rates and decisions on the format, wording and dissemination of the questionnaire were evidence-based.

However, despite the concerted efforts made to maximise the number of responses, the valid response rate was low at $12.7 \%$. It is possible that the reported response rate is an underestimation in this instance due to the difficulty in maintaining an up-to-date register of doctors currently working in Ireland. The high number of responses excluded from this study $(\mathrm{n}=161)$ supports this possibility. In terms of mode of delivery of the questionnaire, telephone-based and paper-based strategies have been shown to be more effective, but due to resource limitations a web-based approach was chosen. ${ }^{37}$ The response 
rate therefore requires consideration when generalising the findings of this survey. Furthermore, the high level of non-responders is also a cause for concern, as it has been demonstrated that non-response to a survey can be attributed, at least in part, to a lack of value placed on the importance of the topic in question. ${ }^{37}$ It is possible that the low response rate reflects the fact that PA counselling remains a low priority for some doctors in practice. This is an important question raised by this study that requires further examination.

Selection bias is a commonly cited limitation within the PA counselling literature and it is possible that doctors who engage in regular PA and enthusiastic proponents of PA counselling were more motivated to participate in this study. ${ }^{22435} 38-41$ Therefore, it is possible that the high level of enquiry regarding PA levels in patients and the reported level of PA counselling activities undertaken in clinical encounters may be an overestimation of the real levels in practice and perhaps, an underestimation of the barriers to undertaking such activities within the clinical setting.

While there are several studies examining the knowledge, attitudes and practice of GPs in relation to PA counselling, less attention has been paid to the role of the hospital doctor in PA counselling at both the national and international levels, despite the increasing responsibilities placed on doctors to undertake brief interventions through the introduction of frameworks such as MECC in Ireland and the UK. This study goes some way towards addressing this knowledge deficit in Ireland. However, the need for a qualitative study designed to further tease out the barriers and facilitators identified in this study is indicated. Moreover, a study of doctors from other specialities, using the same methodology as employed in this study, would facilitate robust comparison of the barriers and facilitators to PA counselling in hospitals and primary care to ensure that any interventions to support doctors in their counselling pursuits meet the needs of doctors, regardless of the setting.

Acknowledgements The authors wish to acknowledge the Royal College of Physicians of Ireland and in particular, the members of the Royal College of Physicians of Ireland Physical Activity Policy Group, for their support in completing this research project.

Contributors All authors were involved in the conceptualisation, design and conduction of the study. SOB and LP cleaned, analysed and interpreted the data. All authors were involved in the drafting and revision of the manuscript for intellectual content, and all approved the final version of the article.

Funding The authors have not declared a specific grant for this research from any funding agency in the public, commercial or not-for-profit sectors.

\section{Competing interests None declared.}

Patient consent for publication Not required.

Ethics approval This study was approved by the Royal College of Physicians of Ireland Research Ethics Committee.

Provenance and peer review Not commissioned; externally peer reviewed.

Data availability statement Data may be obtained from a third party and are not publicly available.

Open access This is an open access article distributed in accordance with the Creative Commons Attribution Non Commercial (CC BY-NC 4.0) license, which permits others to distribute, remix, adapt, build upon this work non-commercially, and license their derivative works on different terms, provided the original work is properly cited, appropriate credit is given, any changes made indicated, and the use is non-commercial. See: http://creativecommons.org/licenses/by-nc/4.0/.

\section{REFERENCES}

1. Beaulac J, Carlson A, Boyd RJ. Counseling on physical activity to promote mental health. Can Fam Physician 2011;57:399-401.

2. Health Service Executive. Making every contact count [Internet]. Dublin: HSE Health and Wellbeing, 2018. Available: https://www. hse.ie/eng/about/who/healthwellbeing/making-every-contact-count/ [Accessed 3 Mar 2019].

3. GC V, Wilson ECF, Suhrcke M, et al. Are brief interventions to increase physical activity cost-effective? A systematic review. $\mathrm{Br} J$ Sports Med 2016;50:408-17.

4. Academy of Medical Royal Colleges. Exercise: the miracle cure and the role of the doctor in promoting it. London: Academy of Medical Royal Colleges, 2015.

5. Kohl HW, Craig CL, Lambert EV, et al. The pandemic of physical inactivity: global action for public health. Lancet 2012;380:294-305.

6. RCPI Policy Group on Physical Activity. Physical activity: a prescription for a wonder drug. The evidence. Dublin: RCPI, 2016.

7. National Institute of Clinical Excellence. Ph 44. physical activity: brief advice for adults in primary care. Manchester: NICE, 2013.

8. Orrow G, Kinmonth A-L, Sanderson S, et al. Effectiveness of physical activity promotion based in primary care: systematic review and meta-analysis of randomised controlled trials. BMJ 2012;344:e1389.

9. Elley CRet al. Effectiveness of counselling patients on physical activity in general practice: cluster randomised controlled trial. BMJ 2003;326:793.

10. Windt J, Windt A, Davis J, et al. Can a 3-hour educational workshop and the provision of practical tools encourage family physicians to prescribe physical activity as medicine? A pre-post study. BMJ Open 2015;5:e007920.

11. Public Health England. Making every contact count (MECC): practical resources [Internet]. London: Public Health England, 2016. Available: https://www.gov.uk/government/publications/makingevery-contact-count-mecc-practical-resources

12. Health Service Executive. Making every contact count: a health and behaviour change framework and implementation for health professionals in the Irish health service. Dublin: HSE Health and Wellbeing Division, 2016.

13. Public Health England. Everybody active, everyday: what works - the evidence. London: Public Health England, 2014.

14. Public Health England, NHS England. Making every contact count (MECC): consensus statement. London: Public Health England, 2016.

15. Public Health England. Everybody active every day: 2 years on. An update on the National physical activity framework. London: Public Health England, 2017.

16. Gorin AA, Phelan S, Hill JO, et al. Medical triggers are associated with better short- and long-term weight loss outcomes. Prev Med 2004;39:612-6.

17. Barrett EM, Darker CD, Hussey J. Promotion of physical activity in primary care: knowledge and practice of general practitioners and physiotherapists. J Public Health 2013;21:63-9.

18. Thornton JS, Frémont $\mathrm{P}$, Khan $\mathrm{K}$, et al. Physical activity prescription: a critical opportunity to address a modifiable risk factor for the prevention and management of chronic disease: a position statement by the Canadian Academy of sport and exercise medicine. Br J Sports Med 2016;50:1109-14.

19. Royal College of Physicians of Ireland. About us [Internet]. Dublin: RCPI, 2017. Available: https://www.rcpi.ie/about-us/

20. Lock C, Wilson G, Kaner E. Survey of general practitioners' attitudes to prevention: repeat of a World Health Organisation collaborative study questionnaire. In: A survey of general practitioners' knowledge, attitudes and practices regarding the prevention and management of alcohol-related problems: an update of a World Health Organisation survey ten years on. Newcastle University Newcastle; 2009.

21. Petrella RJ, Lattanzio CN, Overend TJ. Physical activity counseling and prescription among Canadian primary care physicians. Arch Intern Med 2007;167:1774-81.

22. Chatterjee R, Chapman T, Brannan MG, et al. Gps' knowledge, use, and confidence in national physical activity and health guidelines and tools: a questionnaire-based survey of general practice in England. Br J Gen Pract 2017;67:e668-75. 
23. Kennedy MF, Meeuwisse WH. Exercise counselling by family physicians in Canada. Prev Med 2003;37:226-32.

24. Wheeler PC, Mitchell R, Ghaly M, et al. Primary care knowledge and beliefs about physical activity and health: a survey of primary healthcare team members. BJGP Open 2017;1.

25. Cho H-J, Sunwoo S, Song Y-M. Attitudes and reported practices of Korean primary care physicians for health promotion. $J$ Korean Med Sci 2003;18:783-90.

26. Bull FC, Schipper EC, Jamrozik K, et al. How can and do Australian doctors promote physical activity? Prev Med 1997;26:866-73.

27. Faculty of Sport and Exercise Medicine UK. Moving medicine [Internet] Edinburgh: FSEM, 2018. Available: http://movingmedicine.ac.uk/

28. American College of Sports Medicine, Exercise is Medicine in action: healthcare providers [Internet]. Indiana: American College of Sports Medicine, 2017. Available: http://www.exerciseismedicine.org/ support_page.php/healthcare-providers/

29. O' Brien M, O' Reilly OJ, O' Sullivan D, et al. Developing a national undergraduate curriculum for health professionals in Ireland on health behaviour change (making every contact count). Int $J$ Integr Care 2017;17:A160.

30. Hauer KE, Carney PA, Chang A, et al. Behavior change counseling curricula for medical trainees: a systematic review. Acad Med 2012;87:956-68.

31. Dacey ML, Kennedy MA, Polak R, et al. Physical activity counseling in medical school education: a systematic review. Med Educ Online 2014;19:24325.

32. Evans DS, Martin L, Neeson B, et al. Brief interventions and motivational interviewing: literature review and guidance for practice. Dublin, Ireland: HSE, 2011.
33. Ampt AJ, Amoroso C, Harris MF, et al. Attitudes, norms and controls influencing lifestyle risk factor management in general practice. BMC Fam Pract 2009;10:59.

34. Phillips K, Wood F, Spanou C, et al. Counselling patients about behaviour change: the challenge of talking about diet. $\mathrm{Br} J$ Gen Pract 2012;62:e13-21.

35. Lambe B, Collins C. A qualitative study of lifestyle counselling in general practice in Ireland. Fam Pract 2010;27:219-23.

36. Sallis R, Franklin B, Joy L, et al. Strategies for promoting physical activity in clinical practice. Prog Cardiovasc Dis 2015;57:375-86.

37. VanGeest JB, Johnson TP, Welch VL. Methodologies for improving response rates in surveys of physicians: a systematic review. Eval Health Prof 2007;30:303-21.

38. Stanford FC, Durkin MW, Blair SN, et al. Determining levels of physical activity in attending physicians, resident and fellow physicians and medical students in the USA. Br J Sports Med 2012;46:360-4.

39. Smith AW, Borowski LA, Liu B, et al. U.S. primary care physicians' diet-, physical activity-, and weight-related care of adult patients. Am J Prev Med 2011;41:33-42.

40. Schneider S, Diehl K, Bock C, et al. Modifying health behavior to prevent cardiovascular diseases: a nationwide survey among German primary care physicians. Int J Environ Res Public Health 2014;11:4218-32.

41. Frank E, Tong E, Lobelo F, et al. Physical activity levels and counseling practices of U.S. medical students. Med Sci Sports Exerc 2008;40:413-21. 